Foggie, A. (1962). Symp. zool. Soc. Lond., 6, 51.

Fulton, F., and Dumbell, K. R. (1949). F. gen. Microbiol., 3, 97. Habel, K.'(1962). F. exp. Med., 115, 181.

(1963). Ann. Rev. Microbiol., 17, 167.

Harnden, D. G. (1964). Amer. J. hum. Genet., 16, 204.

Heath, R. B., Fairley, G. H., and Malpas, J. S. (1964). Brit. F. Haemat., 10, 365 .

Huebner, R. J., Rowe, W. P., Turner, H. C., and Lane, W. T. (1963). Proc. nat. Acad. Sci. (W Wash.), 50, 379.

Koprowski, H., Love, R., and Koprowska, I. (1957). Tex. Rep. Biol. Med., 15, 559.

Lindenmann, J. (1963). Proc. Soc. exp. Biol. (N.Y.), 113, 85.

and Klein, P. A. (1965). F. Immunol., 94, 461.

Massimo, L., Vianello, M. G., Dagna-Bricarelli, F., and Tortorolo, G. (1965). Brit. med. F., 2, 172.

Moore, A. E. (1949). Cancer (Philad.), 2, 525.

- (1951). Ibid., 4, 375 .

Moorhead, P. S., Nowell, P. C., Mellman, W. J., Battips, D. M., and Hungerford, D. A. (1960). Exp. Cell Res., 20, 613.

Nichols, W. W. Leven, A., Hall, B., and Ostergren, G. (1962). Heriditas (Lund.), 48, 367.

O'Reilly, K. J., Smith, C. E. G., McMahon, D. A., Wilson, A. L., and Robertson, j. M. (1965). ł. Hyg. (Lond.), 63, 213.

Pelner, L., Fowler, G. A., and Nauts, H. C. (1958). Acta med. scand., 162, Suppl. No. 338, p. 1.
Porter, G. H. (1963). Arch. intern. Med., 3, 572.

Price, W. H., Lee, R. W., Gunkel, W. F., and O'Leary, W. (1961). Amer. F. trop. Med. Hyg., 10, 403.

Sever, J. L. (1962). F. Immunol,, 88, 320.

Shah, K. V., Cole, G. A., Russ, S. B., Needy, C. L., and Buescher, E. L. (1962)., Symposium Csav. Biology of Viruses of the Tick-borne Encephalitis Complex, Praha, p. 303.

Shein, H. M., and Enders, J. F. (1962). Proc. Soc. exp. Biol. (N.Y.), 109, 495.

Smith, C. E. G. (1956). Nature (Lond.), 178, 581.

Turner, L. H., and Armitage, P. (1962). Bull. Wld Hlth Org., 27, 717 .

Smorodintsev, A. A. (1963). Proc. 7th int. Congr. trop. Med. Malar., Rio de Janeiro.

Southam, C. M. (1963). F. Pediat., 63, 138.

and Moore, A. E. (1951). Amer. F. trop. Med., 31, 724.

Thompson, W. R. (1947). Bact. Rev., 11, 115.

Webb, H. E., and Burston, J. B. (1966). Trans. roy. Soc. Med. (in press). - and Chatterjea, J. B. (1962). Brit. 7. Haemat., 8, 401.

Wheelock, E. F., and Dingle, J. H. (1964). New Engl. F. Med., 271, 64 J. Wiedemann, H.-R. (1964). Lancet, 1, 721 .

Yabe, Y., Samper, L., Bryan, E., Taylor, G., and Trentin, J. J. (1964). Science, 143, 46.,

Zilber, L. A. (1962). Acta Un. int. Cancr., 18, 127.

\title{
Observations on Infective Drug Resistance in Britain
}

\author{
H. WILLIAMS SMITH,* D.SC., PH.D., F.R.C.V.S., DIP.BACT., M.C.PATH. ; SHEILA HALLS,* B.SC.
}

Brit. med. F., 1966, 1, 266-269

Infective drug resistance is now known to be important in the spread of drug resistance among members of the Enterobacteriaceae. It has been studied extensively in Japan, where it was first discovered in 1959 ; the results have been reviewed by Watanabe (1963). By comparison little has been published in other countries. Observations on the situation in Britain have been made by Datta (1962), Anderson and Datta (1965), and Anderson and Lewis (1965). These have dealt mainly with Salmonella typhimurium.

It was felt that an impression of the importance of infective resistance as a cause of drug resistance in the Enterobacteriaceae in Britain might be obtained by assessing its incidence in Escherichia coli, since these organisms form the bulk of the enterobacteriaceal flora of the alimentary tract of man and domestic animals. The results of such a survey are reported in this paper. So are studies involving the transfer, in vitro, of resistance from non-pathogenic $E$. coli isolated from the faeces of man, calves, pigs, and fowls to some of the principal Salmonella and $E$. coli serotypes that cause disease in these species. The experiments included the use, as donors, of $E$. coli that were tetracycline-resistant only, organisms that are often found in the faeces of pigs and fowls fed diets containing tetracyclines (Smith and Crabb, 1957). The results of transferring resistance among Salmonella serotypes and from them to pathogenic serotypes of $E$. coli are also described.

\section{Methods}

\section{Transfer of Resistance}

Nutrient broth (Oxoid No. 2) in 10-ml. amounts was seeded with $0.02 \mathrm{ml}$. of a 24 -hour broth culture of the "donor" strain and $0.1 \mathrm{ml}$. of a similar culture of the "recipient" strain. The mixed culture was incubated at $37^{\circ} \mathrm{C}$. for 24 hours and centrifuged. The deposit was inoculated heavily on to a Petri plate of solid medium containing a drug to which the donor was resistant and the recipient was initially sensitive (referred to as selection medium). The plate was then incubated at $37^{\circ} \mathrm{C}$. for 24 hours and examined for colonies of the recipient strain. If any were found a few were

* Animal Health Trust, Stock, Essex. picked, purified by plating on solid medium, and a single colony was then picked into broth and the drug resistance pattern of the resulting culture determined. Controls consisting of broth that had been inoculated with the recipient culture only were always kept.

When the recipient was a Salmonella sp., deoxycholate citrate agar was used as the basal selection medium, the inoculum sometimes first being incubated in selenite $F$ medium at $37^{\circ} \mathrm{C}$. for 18 hours in the hope of suppressing the $E$. coli if they were of the kind that multiplied on deoxycholate citrate agar. When the recipient was $E$. coli, MacConkey agar was employed as the basal selection medium, except when the donor was also a strain of $E$. coli. In the latter event nutrient agar containing washed erythrocytes was used if either donor or recipient was haemolytic. When both were non-haemolytic differentiation was usually an impossible task. When the donor was streptomycin-sensitive the situation was overcome by preparing a chromosome mutant from the recipient that was streptomycin-resistant and incorporating streptomycin as an additional drug in the selection medium. On a few occasions a strain of $E$. coli naturally resistant to furazolidone only was used in a similar manner, the additional drug added to the basal selection medium in this case being furazolidone. Normally the drug employed in the selection medium was streptomycin (40-80 $\mu \mathrm{g} . / \mathrm{ml}$.$) , oxytetracycline (20-40 \mu \mathrm{g} . / \mathrm{ml}$.$) , chloramphenicol$ (20 $\mu \mathrm{g} . / \mathrm{ml}$.$) , ampicillin (20-30 \mu \mathrm{g} . / \mathrm{ml}$.), neomycin $(20 \mu \mathrm{g} . / \mathrm{ml}$.), or furazolidone $(10-20 \mu \mathrm{g} . / \mathrm{ml}$.).

\section{Sensitivity Tests}

Approximately $0.15 \mathrm{ml}$. of a 1 in 50 dilution of a 24-hour broth culture of the strain to be tested was spread evenly over the surface of a dried Petri plate of MacConkey agar, and disks containing different drugs were then applied at approximately equal distances apart. The amounts of the drugs used were $50 \mu \mathrm{g}$. of streptomycin (S), oxytetracycline (T), chlortetracycline $(\mathrm{T})$, chloramphenicol (C), and neomycin $(\mathrm{N})$, and $25 \mu \mathrm{g}$. of ampicillin $(A)$ and furazolidone $(F)$, and $150 \mu \mathrm{g}$. of sulphadimidine (Su). The plates were incubated at $37^{\circ} \mathrm{C}$. for 24 hours and read. Except in the case of sulphadimidine no difficulty was experienced in making the readings; the zones of inhibition surrounding the disks were either wide or very narrow or non-existent. All cultures that appeared to be sulphadimidine-resistant were retested on nutrient agar in which sulphonamide inhibitors had been neutralized by the addition of lysed horse 
erythrocytes (Smith and Crabb, 1957). Similar results were always obtained with oxytetracycline and chlortetracycline; in the text they are always referred to collectively as tetracyclines $(T)$.

\section{Isolation of Resistant Strains of E. coli from Faeces}

Each faecal swab was rubbed evenly over the whole surface of a dried Petri plate of MacConkey medium, and disks containing the seven different drugs referred to above were applied to the surface of the medium. The plates were incubated at $37^{\circ}$ for 24 hours. Lactose-fermenting colonies resembling $E$. coli that grew in the proximity of the disks were subcultured on to MacConkey medium, and a single colony from this plating was selected. If it gave a positive reaction to the Eijkman test it was accepted as $E$. coli and was submitted to a sensitivity test in the manner previously described.

\section{Results}

Incidence of Infective Resistance in the E. coli Population of the Faeces of Human Beings and Domestic Animals

The results of examining faecal swabs of healthy human beings, calves, pigs, and fowls for the presence of resistant strains of $E$. coli are summarized in Table I. The human beings belonged to different households, and the fowls and pigs to different farms. All the calves had originated from different farms and were sampled immediately they arrived at an intensive unit in Essex; they had existed as a group for less than 12 hours. Most of the swabs from all four species contained resistant $E$. coli, many yielding strains of more than one resistance pattern. In general the incidence of strains resistant to any particular drug in the swabs from any of the four species correlated with the estimated degree of exposure to that drug of the particular population they represented.

TABLE I.-Incidence of Drug-resistant E. coli in Faecal Swabs of Human Beings, Calves, Pigs, and Fowls

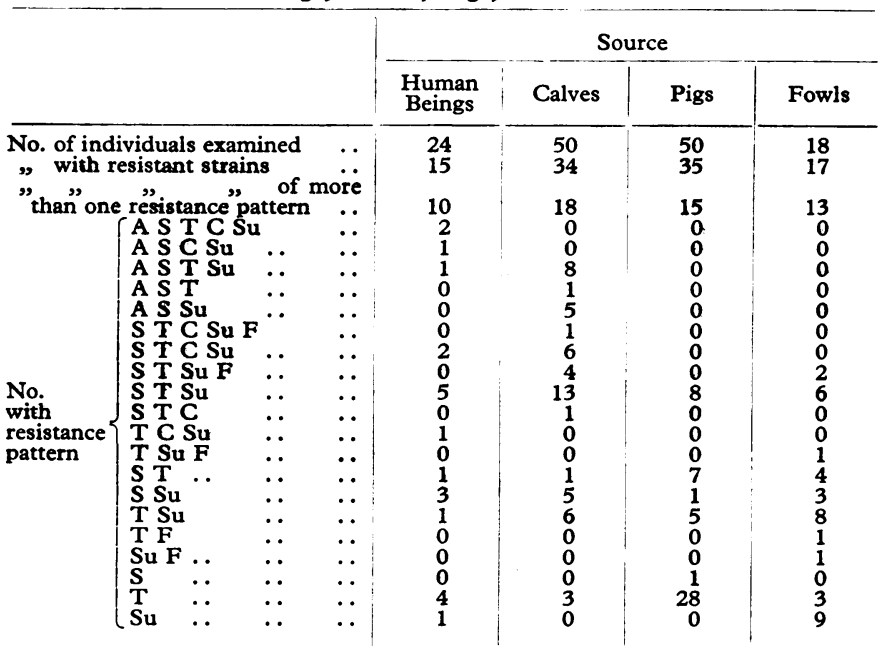

$A=$ Ampicillin.
$S u=$ Sulphonamide.
$F=$ Streptomycin.

A representative selection of the strains shown in Table I, 20 per species, were examined to determine whether or not their resistance was of the infective type ; the results are given in Table II. At first a strain of $S$. dublin was used as recipient because it had been shown in preliminary experiments to be relatively suitable for this purpose. By this means the resistance of 46 of the 80 strains of $E$. coli was shown to be of the infective type; a further 13 infectively resistant strains were detected employing $S$. typhimurium or $S$. gallinarum as recipients. About half of these 59 strains were detected at the first test. It was necessary to perform 2 to 10 tests before the others were ultimately detected. The reason for this in most cases appeared to be a combination of low transfer frequency and the ability of the donor $E$. coli strain to grow reasonably well on deoxycholate citrate agar even after the mixed cultures were incubated in selenite medium.

Infective resistance was demonstrated in a further five strains by means of a streptomycin-resistant mutant of a porcine enteropathogenic strain of $E$. coli, antigenic formula $0141: \mathrm{K} 85 \mathrm{ab} \rightarrow$ $\mathrm{K} 85 \mathrm{ac}$, as recipient, and in another five with the non-pathogenic strain of $E$. coli resistant to furazolidone only.

With two exceptions the complete pattern of resistance was transferred intact in all the experiments referred to above. One exception was the failure to transfer furazolidone resistance from the six strains of $E$. coli in which it formed part of the resistance pattern. The other exception concerned the 10 strains that included ampicillin in their resistance pattern. From only three was the complete pattern transferred intact. From the other seven the complete pattern minus ampicillin resistance was transferred. The' ampicillin resistance of these seven strains was possibly mutational in origin, since ampicillinresistant mutants were easily obtained in the present work from several strains of $E$. coli, including pathogenic ones, by inoculating them heavily on to solid media containing $20 \mu \mathrm{g}$. of ampicillin per $\mathrm{ml}$. The minimum inhibitory concentration of ampicillin for these mutants varied from 100 to $400 \mu \mathrm{g} . / \mathrm{ml}$.

Apart from those included in Table II another 10 strains of $E$. coli that were resistant to the tetracyclines only-five from pigs and five from fowls-were examined to determine whether their resistance was of the infective type. This was done because these $E$. coli strains are the kind that constitute the bulk of the $E$. coli flora of the alimentary tract of pigs and fowls that are fed commercially on diets containing low levels of tetracyclines in the hope of increasing their growth rate (Smith and Crabb, 1957). With the S. dublin strain and the streptomycin-resistant mutant of the enteropathogenic pig $E$. coli $0141: \mathrm{K} 85 \mathrm{ab} \rightarrow 85 \mathrm{ac}$ as recipients the resistance of four of the five pig strains was shown to be infective, tetracycline resistance being transferred from three of the strains to $S$. dublin, and from three to the enteropathogenic E. coli. By a similar procedure, but substituting a streptomycin-resistant mutant of a fowl pathogenic $E$. coli, $02: \mathrm{K} 1: \mathrm{H} 6$, for the enteropathogenic pig strain, the resistance of all of the five fowl strains was shown to be infective, tetracycline resistance being transferred from four of the strains to $S$. dublin and from three to the pathogenic fowl strain.

TABLE II.-Incidence of Infective Resistance Among Drug-resistant Strains of E. coli Isolated from the Faeces of Human Beings, Calves, Pigs, and Fowls

\begin{tabular}{|c|c|c|c|c|c|c|c|c|}
\hline \multirow{3}{*}{$\begin{array}{l}\text { Resistance } \\
\text { Pattern }\end{array}$} & \multicolumn{8}{|c|}{ Source of Strains } \\
\hline & \multicolumn{2}{|c|}{ Human Beings } & \multicolumn{2}{|c|}{ Calves } & \multicolumn{2}{|c|}{ Pigs } & \multicolumn{2}{|c|}{ Fowls } \\
\hline & $\begin{array}{c}\text { No. } \\
\text { Tested }\end{array}$ & $\begin{array}{l}\text { No. } \\
\text { I.R.* }\end{array}$ & $\begin{array}{l}\text { No. } \\
\text { Tested }\end{array}$ & $\begin{array}{l}\text { No. } \\
\text { I.R. }\end{array}$ & $\underset{\text { Tested }}{\text { No. }}$ & $\begin{array}{l}\text { No. } \\
\text { I.R }\end{array}$ & $\begin{array}{c}\text { No. } \\
\text { Tested }\end{array}$ & $\begin{array}{l}\text { No. } \\
\text { I.R. }\end{array}$ \\
\hline 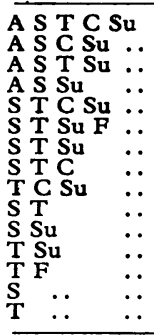 & $\begin{array}{l}2 \\
1 \\
1 \\
0 \\
2 \\
0 \\
5 \\
0 \\
1 \\
1 \\
3 \\
0 \\
0 \\
0 \\
4 \\
\end{array}$ & $\begin{array}{l}2 \\
1 \\
1 \\
0 \\
2 \\
0 \\
5 \\
0 \\
1 \\
1 \\
3 \\
0 \\
0 \\
0 \\
3 \\
\end{array}$ & $\begin{array}{l}0 \\
0 \\
4 \\
2 \\
4 \\
3 \\
4 \\
1 \\
0 \\
1 \\
0 \\
0 \\
0 \\
0 \\
1 \\
\end{array}$ & $\begin{array}{l}0 \\
0 \\
4 \\
1 \\
3 \\
1 \\
4 \\
1 \\
0 \\
1 \\
0 \\
0 \\
0 \\
0 \\
1 \\
\end{array}$ & $\begin{array}{r}0 \\
0 \\
0 \\
0 \\
0 \\
0 \\
4 \\
0 \\
0 \\
2 \\
0 \\
3 \\
0 \\
1 \\
10 \\
\end{array}$ & $\begin{array}{l}0 \\
0 \\
0 \\
0 \\
0 \\
0 \\
3 \\
0 \\
0 \\
2 \\
0 \\
3 \\
0 \\
1 \\
7 \\
\end{array}$ & $\begin{array}{l}0 \\
0 \\
0 \\
0 \\
0 \\
2 \\
3 \\
0 \\
0 \\
3 \\
2 \\
6 \\
1 \\
0 \\
3 \\
\end{array}$ & $\begin{array}{l}0 \\
0 \\
0 \\
0 \\
0 \\
0 \\
2 \\
2 \\
0 \\
0 \\
3 \\
3 \\
2 \\
5 \\
1 \\
0 \\
3 \\
\end{array}$ \\
\hline Total & 20 & 19 & 20 & 16 & 20 & 16 & 20 & 18 \\
\hline
\end{tabular}

* Infectively resistant. The complete resistance pattern was transferred except for furazolidone resistance and for the ampicillin resistance of 7 of the 10 ampicillinresistant strains.

\section{Transference of Resistance from Non-pathogenic E. coli to Salmonella and E. coli Serotypes Pathogenic for Man and Domestic Animals}

The details of donor and recipient cultures employed in attempts to transfer drug resistance to the principal Salmonella 
and $E$. coli serotypes that cause disease in man, calves, pigs, and fowls from non-pathogenic $E$. coli isolated from the faeces of these species are given in Table III. Apart from strains $\mathrm{H} 1, \mathrm{~B} 258, \mathrm{P} 14$, and $\mathrm{C} 9$ not being used in mixed culture experiments with the $E$. coli pathogenic to man, calf, and fowl, attempts were made to transfer resistance from all the strains listed as donors to all those listed as recipients. The reason for the omission of these $E$. coli from mixed culture experiments was the impossibility of devising a selection medium to distinguish donor from recipient. Owing to their haemolytic nature this was overcome in the case of the $E$. coli pathogenic to pigs by using blood agar as the basis of the selection medium ; all the donors were non-haemolytic. It was overcome in the experiment employing $\mathrm{C} 12$ and $\mathrm{P} 17$ as donors by using as recipients chromosome mutants of the pathogenic $E$. coli that were streptomycin-resistant, and including streptomycin as well as oxytetracycline in the selection medium; the mutants were prepared in the laboratory. $\mathrm{C} 12$ and P17, being tetracyclineresistant only, were included in these experiments because they were representative of the $E$. coli found in pigs and fowls fed diets containing tetracyclines.

TABLE III.-Details of Experiments Using Non-pathogenic E. coli as Donors and Salmonella and Pathogenic E. coli Serotypes as Recipients

\begin{tabular}{|c|c|c|c|c|}
\hline \multicolumn{3}{|c|}{ Donor Non-pathogenic $E$. coli Strains } & \multicolumn{2}{|c|}{ Recipient Strains } \\
\hline Identification & Origin & $\begin{array}{l}\text { Resistance } \\
\text { Pattern }\end{array}$ & Identification & $\begin{array}{l}\text { Principal } \\
\text { Host } \\
\text { Pathogen }\end{array}$ \\
\hline $\begin{array}{l}\mathrm{H} 1 \\
\text { B258 } \\
\text { P14 } \\
\text { C9 } \\
\text { P17 } \\
\text { C12 }\end{array}$ & $\begin{array}{cc}\text { Faeces, } & \text { man } \\
, & \text { calf } \\
, & \text { pig } \\
, & \text { fowl } \\
, & \text { pig } \\
, & \text { fowl }\end{array}$ & $\begin{array}{l}\text { S Su T C } \\
\text { A S Su T C } \\
\text { S Su T C } \\
\text { S Su T } \\
T \text { T } \\
T\end{array}$ & $\begin{array}{l}\text { S. typhi } \\
\text { S. paratyphi B } \\
\text { S. typhimurium } \\
\text { S. dublin } \\
\text { S. cholere-suis } \\
\text { S. gallinarum } \\
\text { S. pullorum } \\
\text { E. colli } 0128: \mathrm{K} 67: \mathrm{H} 2 \\
\text { E. coli } 055: \mathrm{K} 59: \mathrm{H} 7 \\
\text { E. coli } \\
\text { 0141: } \\
\text { E. coli } 85 \mathrm{ab} ; \mathrm{K} 88 \mathrm{ab} \\
\text { 0141: } 85 \mathrm{ab} \rightarrow \mathrm{K} 85 \mathrm{ac} \\
\text { E. coli } 02: \mathrm{K} 1: \mathrm{H} 6 \\
\text { E. coli } 011: \mathrm{K} \text {. } \\
\text { E. coli } 078: \mathrm{K} 80 \\
\text { (2 strains) }\end{array}$ & $\begin{array}{l}\text { Man } \\
\text { All species } \\
\text { Calf } \\
\text { Pig } \\
\text { Fowl } \\
\text { Man } \\
\text { ” } \\
\text { Pig } \\
\text { Fowl } \\
\text { Calf }\end{array}$ \\
\hline
\end{tabular}

Apart from the inability to transfer resistance from $\mathrm{P} 17$ to $S$. typhi and $S$. pullorum all the transfer attempts were successful. Several attempts were often necessary before success was achieved, for the same reasons that applied in the studies on the incidence of infective resistance in $E$. coli (see above).

With some exceptions the complete resistance pattern was always found to have been transferred intact. The exceptions were: (1) When P14 was donor the resistance pattern found in the recipient $S$. typhi, S. paratyphi B, S. typhimurium, $S$. cholerae-suis, and $S$. gallinarum cultures was always $S$ Su C ; $T$ resistance was never detected in these recipients irrespective of the drug used in the selection medium. (2) Only the resistance pattern S Su T C was transferred from B258 when either $S \mathrm{~T}$ or $\mathrm{C}$ was used in the selection medium. When $\mathrm{A}$ was used instead the recipients acquired the resistance pattern A, A S, or A S Su.

In other studies using multiple-resistant strains of $E$. coli as donors it was not unusual to isolate recipients that possessed different combinations of the complete resistance pattern of the donor. These different combinations were usually obtained when different drugs were used in the selection medium. Sometimes a variety were obtained when the same drug was used. One extreme example of this was noted in mixed-culture experiments employing an $E$. coli strain to which the resistance pattern A S Su T CN had been transferred in the laboratory as donor and 12 Salmonella strains as recipients. Of 24 colonies picked from the 12 plates of selection medium containing ampicillin only two had the complete resistance pattern A S Su T C N. The other combinations noted were A Su N C (5), A N S (1), A S Su C (1), A N (5), A S (4), and A (6).
Two strains of $E$. coli whose resistance was of the infective type were of special interest because they had been isolated as long ago as March 1956, freeze-dried soon afterwards, and reconstituted for testing in 1965 . They had been isolated from two epidemiologically unrelated outbreaks of diarrhoea in calves very shortly after chloramphenicol became available for use in calves. It was possible to transfer their complete resistance pattern S Su T C to $S$. dublin and $S$. cholerae-suis, the only two cultures with which they were tested.

Infective resistance was also demonstrated in three pathogenic strains of $E$. coli, the only ones tested. These were a human pathogen, 0111: K58:H2 (resistance pattern S Su T), and two pig pathogens, $0147: \mathrm{K} 89 ; \mathrm{K} 88 \mathrm{ac}$ (resistance pattern $\mathrm{S} \mathrm{Su} \mathrm{T}$ ) and $0141: \mathrm{K} 85 \mathrm{ab} \rightarrow \mathrm{K} 85 \mathrm{ac}$ (resistance pattern $\mathrm{T}$ ).

\section{Transfer of Resistance from S. typhimurium to other Salmonella Serotypes and to Pathogenic Serotypes of E. coli}

All attempts to transfer resistance from three unselected resistant strains of $S$. typhimurium to 16 pathogenic strains of $E$. coli were successful. Only 24 different combinations of donor and recipient were studied.

The $E$. coli strains belonged to the following serotypes: $0128: \mathrm{K} 67: \mathrm{H} 2$, $055: \mathrm{K} 59: \mathrm{H} 7$, and 0119:K69 (man); 0141: $\mathrm{K} 85 \mathrm{ab} ; \mathrm{K} 88 \mathrm{ab}, 0141: \mathrm{K} 85 \mathrm{ab} \rightarrow \mathrm{K} 85 \mathrm{ac}, 0147: \mathrm{K} 89 ; \mathrm{K} 88 \mathrm{ac}, 0138:$ $\mathrm{K} 81$, and $08: \mathrm{K} 87 ; \mathrm{K} 88 \mathrm{ab}$ (pig) ; $02: \mathrm{K} 1: \mathrm{H} 6,078: \mathrm{K} 80$, and $011: \mathrm{K}$ ? (fowl); and $078: \mathrm{K} 80$ (calf).

In the experiments with one of the $S$. typhimurium strains the complete resistance pattern $\mathrm{A} \mathrm{Su} \mathrm{T}$ was transferred intact. In those with the other two all the resistance factors were shown to be transferable, but no recipient was isolated that possessed the complete resistance pattern of the donor. The recipients from one of these donors, whose resistance pattern was A S Su T N F, were either A S Su, A S Su N, S Su N, A N, $A, T, N$, or $F$ resistant. Those from the other, whose resistance pattern was $S$ Su T F, were either $S S u, S$ Su T, S Su F, or F resistant.

A small number of attempts were made to transfer resistance from two of the resistant $S$. typhimurium strains to strains of other Salmonella serotypes. Recipient colonies on the selection medium could only be identified by slide-agglutination tests. Even so, it was possible to detect resistance transference in eight experiments, indicating a high transfer frequency. From the strain witl the resistance pattern $S$ Su T F resistance was transferred to a strain of $S$. dublin (A) and $S$. typhimurium (A T). From the strain with the resistance pattern A S Su T N F resistance was transferred to a strain of $S$. cholerae-suis (A S), S. dublin (A and A S Su), and S. gallinarum (A S).

\section{Stability of Infective Resistance}

Twenty-two infectively resistant strains were passaged daily for 10 days in $20-\mathrm{ml}$. amounts of nutrient broth at $37^{\circ} \mathrm{C}$., the necessary subcultures being made with the tip of a platinum wire. Sensitivity tests were performed after each passage. The results are given in Table IV. Loss of resistance by some of the organisms in the culture, as evidenced by the presence around a drug-containing disk of a clearly defined zone of bacterial growth which was less plentiful than the rest of the growth on the plate of medium used for sensitivity-testing, occurred during passage of four of the strains made infectively resistant in the laboratory and four of the strains that had acquired infective resistance naturally. This loss of resistance was first noted at the third to the seventh passage, the proportion of organisms sensitive to one or more of the drugs to which they were initially resistant increasing progressively with passage until at the final passage the change was almost complete. The numbers of different kinds of resistant organisms 
in culture No. 9 (Table IV) at the tenth passage were estimated by means of solid media containing different drugs. The total viable count and that of ampicillin-resistant organisms was $1,000 \times 10^{\circ}$ per ml. The counts of neomycin-resistant, chloramphenicol-resistant, and streptomycin-resistant organisms were only $50 \times 10^{6}, 40 \times 10^{6}$, and $3 \times 10^{6} \mathrm{per} \mathrm{ml}$. respectively. Tests on a small number of colonies from the drug-containing plates of media used for counting revealed that they were either A, A C, ACS, A S, or A N resistant.

TABLE IV.-Effect of Passage in Nutrient Broth on Stability of Infective TABLB IV.- Effect of Passage in Nutrient

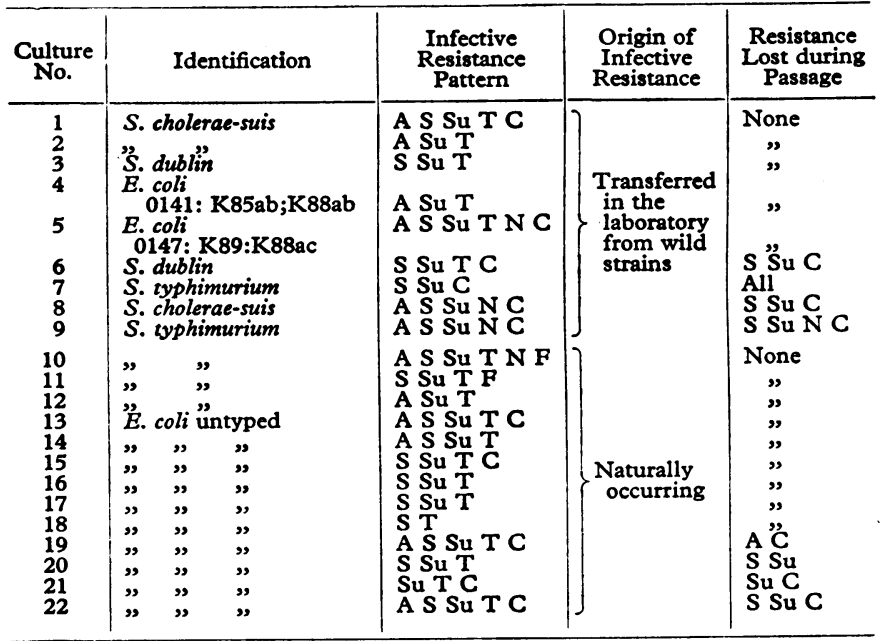

Passage experiments were also performed with 10 strains of non-pathogenic $E$. coli, tetracycline-resistant, and of pig and fowl origin. No loss of resistance was noted. Neither was it noted in 12 similar experiments with $S$. dublin and $E$. coli, pathogenic for pigs and fowls, to which the resistance of some of the 10 strains of non-pathogenic $E$. coli was transferred in the laboratory.

\section{Discussion}

Though our survey was limited in size, the results indicate that infective resistance is probably the most common form of drug resistance among the $E$. coli that inhabit the alimentary tract of human beings, calves, pigs, and fowls in Britain. The fact that it has become so widespread among the human and animal $E$. coli populations during the relatively short antibiotic era, and that so many drugs are involved, makes it unlikely that the de novo emergence of infectively resistant organisms is a rare event. Rather does the reverse seem more probable. The demonstration of infective resistance to streptomycin, sulphonamides, tetracyclines, and chloramphenicol in two unrelated strains of $E$. coli isolated from calves as long ago as 1956 does not support a view that infective resistance is a phenomenon having risen relatively late in the antibiotic era. It is noteworthy that the calves from which the two strains were isolated were among the first in Britain to be treated with chloramphenicol.

The case against the overuse of drugs is now greatly strengthened, because it is apparent that the resistant nonpathogenic $E$. coli which frequently become dominant in the alimentary tract during drug administration are most likely to be infectively resistant. This resistance might be transferred to other non-pathogenic strains of $E$. coli that may be better adapted, in the absence of the selection pressure provided by the presence of the drug, at colonizing the alimentary tract. So long as infectively resistant strains of $E$. coli persist in the alimentary tract there is a danger of their resistance being transferred to any pathogenic member of the Enterobacteriaceae that may enter it.

Since the drug resistance of the non-pathogenic strains of $E$. coli isolated from the alimentary tract of man, calf, pig, and fowl was transferred to the principal Salmonella serotypes and to some of the $E$. coli serotypes pathogenic for these four species of animal, the colonization of the alimentary tract of any one of these species with drug-resistant $E$. coli from any of the others might be considered an undesirable event. Judging from the survey this would appear to be of limited importance at the present time because there was no great difference between the incidence of resistant strains in the various species. It might well be important in the future if a variety of drugs were used excessively in one of the species. The situation developing in calves in intensive units requires watching in this respect. It is noteworthy that the ampicillin-resistant strains of $E$. coli isolated from human beings (Table $\mathrm{I}$ ) originated from human beings who looked after intensively reared calves; the faeces of many of these calves contained ampicillin-resistant E. coli.

The passage experiments revealed a great difference in stability between multiple-resistant strains. It is apparent that under natural conditions in a drug-free environment some of them would soon lose at least a part of their resistance pattern. All the non-pathogenic $E$. coli strains tested that were tetracycline-resistant only, and that are representative of the $E$. coli found in pigs and fowls fed diets containing tetracyclines, showed no loss of resistance on passage. This finding was not unexpected, because previous observations (Smith and Crabb, 1957) had shown that tetracycline-resistant organisms still dominated the $E$. coli flora of the faeces of pigs three to seven months after the practice of feeding tetracyclines was withdrawn. It is noteworthy that in the present work it was possible to transfer resistance from this kind of $E$. coli to most of the Salmonella and $E$. coli serotypes pathogenic for man, calves, pigs, and fowls.

\section{Summary}

In a small survey conducted in 1965 drug-resistant strains of $E$. coli were fairly often found in the faeces of human beings, calves, pigs, and fowls. The resistance of most of these strains, and of two isolated in 1956, was infective.

The resistance of four non-pathogenic strains of $E$. coli isolated from the faeces of a man, a calf, a pig, and a fowl was transferred to the principal Salmonella serotypes, and to some of the $E$. coli serotypes that cause disease in these four species. Similar transfers were performed using as donor $E$. coli strains that were tetracycline-resistant only-strains that are typical of those that dominate the $E$. coli flora of pigs and chickens that are fed commercially on diets containing tetracyclines. The resistance of most of the strains of this type examined was infective.

The multiple resistance of three strains of $S$. typhimurium was transferred to other Salmonella serotypes and to pathogenic serotypes of $E$. coli.

A minority of multiple-resistant strains lost a part or the whole of their resistance pattern during serial passage in broth; this was not observed in strains of $E$. coli resistant to tetracyclines only.

Ampicillin, streptomycin, tetracyclines, chloramphenicol, neomycin, sulphonamides, and furazolidone were all found to be involved in infective drug resistance.

We wish to thank Mrs. L. Stubbs, Miss S. Harding, and Mr. A. Miller for their capable technical help, and Mrs. E. Johnson, Dr. K. C. Sellers, Dr. Joan Taylor, and Mr. J. Walton for advice and assistance in various ways.

\section{REFERENCES}

Anderson, E. S., and Datta, N. (1965). Lancet, 1, 407.

and Lewis, M. J. (1965). Nature (Lond.), 206, 579.

Datta, N. (1962). \%. Hyg. (Lond.), 60, 301.

Smith, H. W., and Crabb, W. E. (1957). Vet. Rec., 69, 24.

Watanabe, T.'(1963). Bact. Rev., 27, 87. 